\title{
Ethnicity based variation in expression of E-cadherin in patients with squamous cell carcinoma of the oral tongue
}

\author{
NICOLA SGARAMELLA ${ }^{1-3}$, TORBEN WILMS ${ }^{4}$, LINDA BOLDRUP $^{1}$, LOTTA LOLJUNG $^{1}$, XIAOLIAN GU $^{1}$, \\ PHILIP J. COATES ${ }^{5}$, PETRA HASSELLÖF ${ }^{1}$, LUIGI CALIFANO ${ }^{3}$, LORENZO LO MUZIO ${ }^{6}$, ROBIN FÅHRAEUS ${ }^{1,5,7}$, \\ LENA NORBERG SPAAK ${ }^{4}$, RENATO FRANCO ${ }^{8}$, GIANPAOLO TARTARO $^{2}$, GIUSEPPE COLELLA $^{2}$, \\ MARIO SANTAGATA $^{2}$, GIOVANNI DELL'AVERSANA ORABONA ${ }^{3}$, FABRIZIO CHIRICO ${ }^{2}$, \\ KARIN DANIELSSON $^{9}$, GIUSEPPE TROIANO ${ }^{6}$, FATIMA ARDITO ${ }^{6}$ and KARIN NYLANDER ${ }^{1}$
}

\begin{abstract}
${ }^{1}$ Department of Medical Biosciences, Umeå University, SE-901 85 Umeå, Sweden; ${ }^{2}$ Multidisciplinary Department of Medical, Surgical and Dental Specialties, Second University of Naples; ${ }^{3}$ Department of Neuroscience Reproductive and Dentistry Sciences, University of Naples Federico II, I-801 38 Naples, Italy; ${ }^{4}$ Department of Clinical Sciences/ENT, Umeå University, SE-901 85 Umeå, Sweden; ${ }^{5}$ RECAMO, Masaryk Memorial Cancer Institute, 65653 Brno, Czech Republic; ${ }^{6}$ Department of Clinical and Experimental Medicine, University of Foggia, I-71122 Foggia, Italy;

${ }^{7}$ University Paris Diderot, INSERM UMRS1162, Paris 75010, France; ${ }^{8}$ Dipartimento Universitario di Anatomia Patologica, Second University of Naples, Piazza Miraglia, I-801 38 Naples, Italy; ${ }^{9}$ Department of Odontology, Umeå University, SE-901 85 Umeå, Sweden
\end{abstract}

Received May 8,2018; Accepted August 31, 2018

DOI: $10.3892 / \mathrm{ol} .2018 .9452$

\begin{abstract}
The oral tongue is the most common site for tumours within the oral cavity. Despite intense research, there has been no improvement in the survival rate for patients with oral tongue squamous cell carcinoma (OTSCC) during the last decades. Differences between oral cancer patients based on ethno-geographical distribution have been reported. The present study used immunohistochemistry to evaluate commonly used markers of cancer cell phenotypes, E-cadherin, $\beta$-catenin and cytokeratins 5 and 19 , in 120 patients with OTSCC. To evaluate the impact of ethnicity, patients from Sweden and Italy were included. A higher proportion of Swedish patients exhibited high expression of E-cadherin in their tumours $(\mathrm{P}=0.039)$, and high levels of E-cadherin in Swedish OTSCC patients that had succumbed to their disease were associated with poor prognosis. These data demonstrated differences in the pathological characteristics of OTSCC between two different European populations. The findings emphasise the need to take ethnicity/geographical location of patients into account when comparing results from different studies of OTSCC.
\end{abstract}

Correspondence to: Professor Karin Nylander or Dr Nicola Sgaramella, Department of Medical Biosciences, Umeå University, Building 6M, 2nd floor, SE-901 85 Umeå, Sweden

E-mail: karin.nylander@umu.se

E-mail: sgaramellanicola12@gmail.com

Key words: E-cadherin, beta catenin, squamous cell carcinoma, oral tongue, ethnicity

\section{Introduction}

The oral tongue, comprising the dorsal, lateral and ventral two-thirds anterior to the circumvallate papillae, is the most commonly tumour affected site within the oral cavity and oral tongue squamous cell carcinoma (OTSCC) is increasing in incidence (1). Moreover, amongst all oral subsites, OTSCC shows the most aggressive behaviour and poor prognosis $(2,3)$. Despite intense research, no improvement in survival has been seen for patients with OTSCC in recent years. New knowledge on this tumour is thus of utmost importance. A complicating factor of large multicentric studies is the ethnic difference seen between patients with oral squamous cell carcinoma (OSCC) (4). To explore this in OTSCC, we analysed groups of patients from two different geographical locations; one from Sweden in Northern Europe and another from Italy in Southern Europe. We analysed E-cadherin, $\beta$-catenin and cytokeratins 5 and 19 in 120 OTSCCs from the two geographical locations to investigate tumour epithelial phenotypes in correlation to patient outcomes.

The epithelial calcium dependent adhesion molecule E-cadherin is associated with squamous differentiation in squamous cell carcinoma (SCC) (5) and oral SCC (OSCC), where low levels associate with poor prognosis (6), metastasis (7) and local recurrence (8). E-cadherin is a commonly used marker of epithelial cell differentiation and is expressed at different levels in individual SCCs. E-cadherin is involved in cell adhesion, being anchored to the cytoskeleton via $\beta$-catenin, a cytoplasmic plaque protein that maintains cell-cell adhesion in the normal oral squamous epithelium. Cytoplasmic $\beta$-catenin correlates with advanced stages and poor differentiation in OTSCC (9). Cytokeratins (CK) are also used as markers of epithelial differentiation and are variably 
expressed in SCC. CKs are intermediate filament proteins that act in specific pair-wise combinations depending on epithelial type and degree of differentiation (10). CK5 and CK19 are expressed by basal epithelial cells (11). CK5 is paired with CK14 in squamous epithelium and CK19 can be seen both in basal squamous cells and simple epithelial cells (10). CK5 is helpful in detection of cervical micro-metastases in head and neck cancer tissue (12). CK5 is almost ubiquitously expressed in head and neck SCC (HNSCC), whereas CK19 is more frequently expressed in tumours from pharynx and larynx (10) and also correlates with poor prognosis in OTSCC (13).

\section{Materials and methods}

Patients. Formalin fixed and paraffin-embedded (FFPE) biopsies from 87 consecutive patients with primary OTSCC available at Clinical Pathology, Umeå University Hospital, Sweden, and 33 patients at Dipartimento Universitario di Anatomia Patologica, Second University of Naples, Italy were included in the study. All tumours were derived from the mobile tongue. All Swedish patients belonged to the Scandinavian ethno-geographical area and all Italian patients to the South-Italian ethno-geographical area. Of the 120 patients, 60 were men and 60 women with a mean age of 63.3 years, ranging from 19-93 years. Of all tumours, $68 \%$ were localised on the lateral border of the oral tongue, $19 \%$ on the ventral side and $3 \%$ on the dorsal side. Lesions were too widespread to state the location in $10 \%$ of the patients. Most of the Swedish patients (54\%) were treated with radiotherapy followed by surgery, whereas $64 \%$ Italian patients were treated by surgery only (Table I). The majority of tumours (109) had previously been analysed for HPV16, p16 and podoplanin $(14,15)$. The mean follow-up time was 47 months (range 1-179 months). Data on survival and cause of death were obtained from the clinical files. The study was performed retrospectively on surplus tissues after diagnosis. The use of redundant tissues for this study was approved by the local Ethical Committee (dnr 01-057 and 03-201). All patient data were anonymised and the study was performed in accordance with European Union regulations and the Declaration of Helsinki. For clinical information and hospital location see Table I.

At the end of the study, $54 \%$ of patients were cancer free, either alive disease free (ADF) or disease free but dead from another cause (DDF). The remaining $46 \%$ were still affected by cancer, dead of disease (DOD), alive with disease (AWD) or dead with disease (DWD) but from a cause other than their OTSCC. Of these latter patients, 44\% showed tumour relapse. Two years after treatment (available for 113 patients, 94\%) 70 were alive and 43 dead, and after five years (available for 93 patients, 82\%) 46 were alive and 47 dead (Table I).

Immunohistochemistry. Sections were pretreated in CC1-buffer (Cell Conditioner 1; Ventana Medical Systems, Inc., Tucson, AZ, USA) at $95^{\circ} \mathrm{C}$ for $36 \mathrm{~min}$ (E-cadherin, $\beta$-catenin), at $95^{\circ} \mathrm{C}$ for $64 \mathrm{~min}(\mathrm{CK} 19)$ and at $100^{\circ} \mathrm{C}$ for 36 min (CK5). Slides were then incubated with primary antibodies diluted in Ventana antibody diluent for $32 \mathrm{~min}$ at $36^{\circ} \mathrm{C}$ and detected using Ultra View Universal DAB Detection kit using a Bench Mark Ultra (Ventana Medical Systems,
Inc.). For slides stained with CK5 an extra step adding an Opti View HQ Linker (Ventana Medical Systems, Inc.) was added before detection. Slides were counterstained with Hematoxylin and Bluing Reagent (Ventana Medical Systems, Inc.). The antibody against E-cadherin (M3612, DAKO; Agilent Technologies, Inc., Santa Clara, CA, USA) was diluted 1:25, anti- $\beta$-catenin (Sigma-Aldrich; Merck KGaA, Darmstadt, Germany) 1:1,500, anti-CK-5 (Novocastra; Leica Microsystems, Inc., Buffalo Grove, IL, USA) 1:100 and anti-CK-19 (M0888, DAKO; Agilent Technologies, Inc.) 1:50.

Scoring. The Quick Score (QS) method was used to assess the overall levels of staining for each antibody. Staining was evaluated by combining the proportion of positive tumour cells $(1=0-4 \%, 2=5-19 \%, 3=20-39 \%, 4=40-59 \%, 5=60-79 \%$ and $6=80-100 \%)$ with intensity of staining $(0=$ negative, $1=$ weak, $2=$ intermediate and $3=$ strong). The final QS was achieved by multiplying these two scores, ranging between 0-18 (16). LB and $\mathrm{KN}$ scored E-cadherin and $\beta$-catenin, 88 samples stained for CK5 and CK19 were scored by LL, PH and KN and the remaining 32 samples by $\mathrm{KN}$ alone.

Statistical analysis. Tumours were grouped according to geographical distribution and level of immunostaining, where low/medium and high tumours were defined as a QS of 0-10 and 12-18 respectively. SPSS v.24 (IBM Corp., Armonk, NY, USA) was used for statistical analyses. Pearson chi-squared test was used to calculate P-values. Kaplan-Meier curves were plotted to perform survival analysis and differences among groups was explored with Log Rank (Mantel-Cox) test. $\mathrm{P}<0.05$ was considered to indicate a statistically significant difference.

\section{Results}

Clinical data. Data on two-year survival were available for all 87 Swedish and 26 of the $33(79 \%)$ Italian patients, where the latter group showed a better 2 -year survival $(\mathrm{P}=0.0005)$.

Immunohistochemistry. All cases were stained for E-cadherin, $\beta$-catenin, CK5 and CK19 (Fig. 1). Positive staining for E-cadherin and $\beta$-catenin was seen in 118 of the 120 cases. All 120 cases expressed CK5, whereas only 76 (63\%) contained CK19 positive tumour cells.

To study potential differences in markers based on ethnicity, patients were sub-divided into Italian and Swedish origins. Patients in the Swedish cohort showed a higher proportion of high E-cadherin tumours (QS 12-18) than Italian patients $(\mathrm{P}=0.039$; Table II).

In Swedish patients that had died of their disease (23 patients) high levels of E-cadherin correlated with poor survival $(\mathrm{P}=0.016)$, whereas no correlation was seen for the six Italian patients that were dead of their disease $(\mathrm{P}=0.842$; Fig. 2$)$. Of the 23 Swedish patients that died of disease, 17 (74\%) had received preoperative radiotherapy (RT) and surgery was then performed on 10 of these; two had received post operative RT and four no RT. Of these latter four, two had received surgery and two no treatment at all. For the six Italian patients, five had received RT only and one also post operative surgery No correlation with survival was seen for $\beta$-catenin, CK5 or CK19 in either group of patients. 
Table I. Clinical data in relation to ethnicity.

\begin{tabular}{|c|c|c|c|}
\hline \multirow[b]{2}{*}{ Characteristics } & \multicolumn{3}{|c|}{ No. of patients (\%) } \\
\hline & Swedish & Italian & Total \\
\hline \multicolumn{4}{|l|}{ Sex } \\
\hline Male & 43 (49) & $17(52)$ & $60(100)$ \\
\hline Female & $44(51)$ & $16(48)$ & $60(100)$ \\
\hline \multicolumn{4}{|l|}{ Age, years } \\
\hline$\leq 40$ & $14(16)$ & $2(6)$ & $16(13)$ \\
\hline $41-65$ & $34(39)$ & $11(33)$ & $45(38)$ \\
\hline$>65$ & $39(45)$ & $20(61)$ & 59 (49) \\
\hline $\mathrm{T} 1 / \mathrm{T} 2$ & $56(64)$ & $24(73)$ & $80(67)$ \\
\hline $\mathrm{N}+$ & $19(22)$ & $13(39)$ & $32(27)$ \\
\hline \multicolumn{4}{|l|}{ Survival } \\
\hline 2-year & $46 / 87(53)$ & $24 / 26(92)$ & $113(94)$ \\
\hline 5-year & $35 / 80(44)$ & $11 / 13(85)$ & $93(78)$ \\
\hline \multicolumn{4}{|l|}{ Treatment } \\
\hline RT followed by surgery & $47(54)$ & $1(3)$ & $48(40)$ \\
\hline RT only & $17(20)$ & $7(21)$ & $24(20)$ \\
\hline Surgery followed by RT & $8(9)$ & $4(12)$ & $12(10)$ \\
\hline Surgery only & $12(14)$ & $21(64)$ & $33(28)$ \\
\hline None & $3(3)$ & $0(0)$ & $3(2)$ \\
\hline Total no. & 87 & 33 & 120 \\
\hline
\end{tabular}

RT, radiotherapy.

\section{Discussion}

Recent advances in diagnosis, surgical management and chemoradiotherapy regimens have only minimally improved the five-year survival for patients with OSCC (17). The present results contribute the important point that E-cadherin levels vary according to ethno-geographical area.

E-cadherin plays a key role in establishing and maintaining intercellular connections and is the main protein of adherens junctions anchoring oral epithelial cells to each other. Dysfunctional E-cadherin-mediated cell adhesion is associated with cancer invasion and metastasis. Many immunohistochemical studies have shown aberrant E-cadherin expression in SCC of the head and neck (HNSCC), and downregulation of E-cadherin has been reported to indicate poor prognosis in OTSCC (18). Those results contrast with our data showing that higher expression of E-cadherin correlates with poor disease-free survival. However, the results from these two studies are not directly comparable as not only different antibodies were used, which is known to affect results (19), but also different methods to evaluate staining. On the other hand, our results are in concordance with a recent study of laryngeal SCC, using a similar analysis with calculation of percent as well as staining intensity of E-cadherin positive tumour cells (20). Variability in the previously published results of E-cadherin in HNSCC, OSCC and OTSCC probably also depend on sample size, sample types included and their geographical location.
Table II. Expression levels of E-cadherin, $\beta$-catenin, CK5 and CK19 in relation to ethnicity.

\begin{tabular}{|c|c|c|c|}
\hline \multirow[b]{2}{*}{ Expression } & \multicolumn{3}{|c|}{ No. of patients (\%) } \\
\hline & $\begin{array}{l}\text { Swedish, } \\
(\%)\end{array}$ & $\begin{array}{c}\text { Italian, } \\
(\%)\end{array}$ & P-value \\
\hline \multicolumn{4}{|l|}{ E-cadherin } \\
\hline QS 0-10 & $54(62)$ & $27(82)$ & 0.039 \\
\hline QS 12-18 & $33(38)$ & $6(18)$ & \\
\hline \multicolumn{4}{|l|}{$\beta$-catenin } \\
\hline QS 0-10 & $70(80)$ & $31(94)$ & 0.071 \\
\hline QS 12-18 & $17(20)$ & $2(6)$ & \\
\hline \multicolumn{4}{|l|}{ CK5 } \\
\hline QS 0-10 & $48(55)$ & $22(67)$ & 0.254 \\
\hline QS 12-18 & $39(45)$ & $11(33)$ & \\
\hline \multicolumn{4}{|l|}{ CK19 } \\
\hline QS 0-10 & $78(90)$ & $31(94)$ & 0.468 \\
\hline QS 12-18 & $9(10)$ & $2(6)$ & \\
\hline Total no. & 87 & 33 & 120 \\
\hline
\end{tabular}

In the present study, we investigated patients from Sweden and Italy to examine the potential geographic variation in phenotype and phenotype-related clinical outcome in OTSCC patients. Better survival was seen in Italian patients, even though more of the Italian patients had nodal metastasis at diagnosis (39\% vs. $22 \%$ of the Swedish patients). As survival is influenced by treatment and most Swedish patients had received neo-adjuvant radiotherapy in contrast to the Italian group, no conclusions can be drawn from the difference in survival data seen in this study. Nonetheless, differences in protein expression between Swedish and Italian patients show biological variation between tumours in different patient populations. Whilst we have not studied the underlying reasons for these variations, there are some obvious potential factors that may influence tumour phenotypes between Sweden and Italy, including the effects of different diets, where the Mediterranean diet typical for our Italian cohort is known to influence the incidence and nature of oral cancer $(21,22)$. An alternative and non-exclusive factor would be the use of different tobacco products, where snus usage is common in Sweden and influences the oral microbiome $(23,24)$, known to be important for OTSCC (25).

In summary, the present study shows that levels of E-cadherin vary between patients based on ethno-geographical distribution. This finding can help explain the inconsistencies seen in studies from different parts of the World that often use the same markers as surrogates for cancer cell phenotypes and their association with clinical outcome. Further studies are required to explain the reasons for the different phenotypes of OTSCC in Northern and Southern Europe, but, similar to other worldwide geographical cancer variations, factors including diet and lifestyle such as smoking habits are prime candidates to account for the differences we have observed (4). 
CK5

QS 12

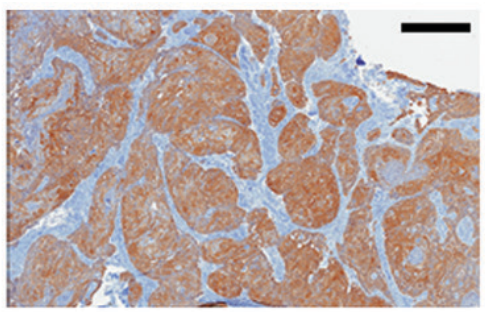

CK19

QS 6

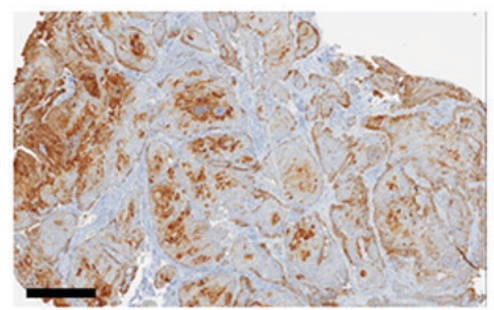

E-cadherin QS 18
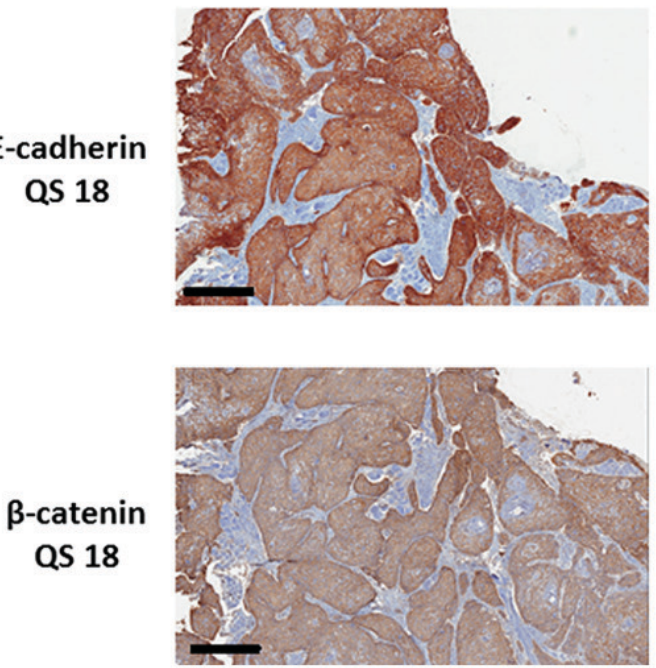
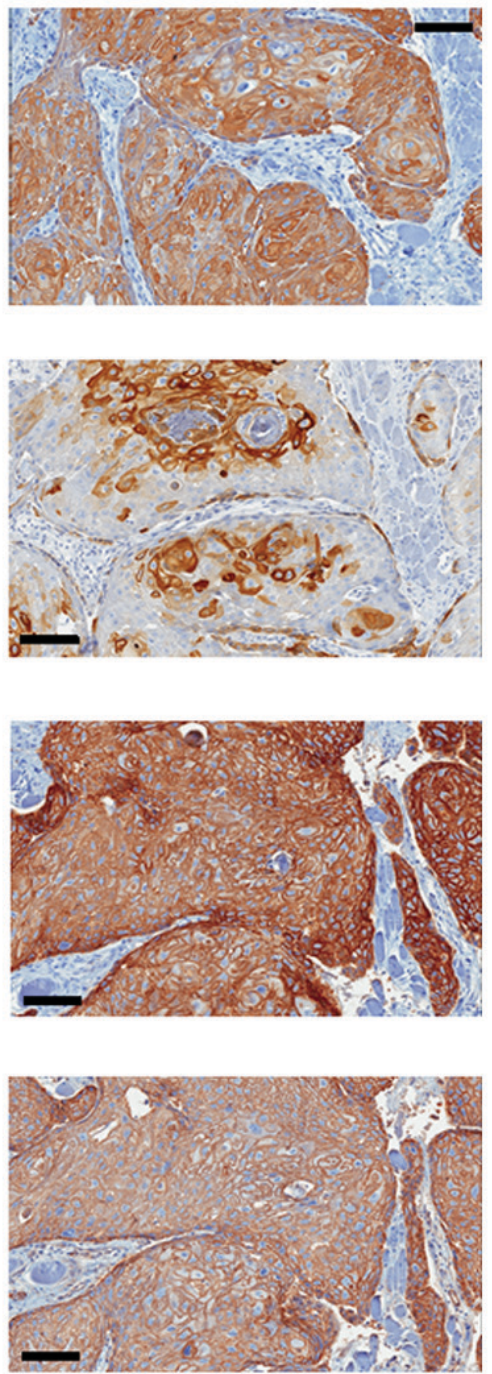

Figure 1. Examples of Quick Score and representative images of immunostaining of OTSCC samples are shown as indicated. Left scale bar, $400 \mu \mathrm{m}$; right scale bar, $100 \mu \mathrm{m}$. OTSCC, oral tongue squamous cell carcinoma.

A

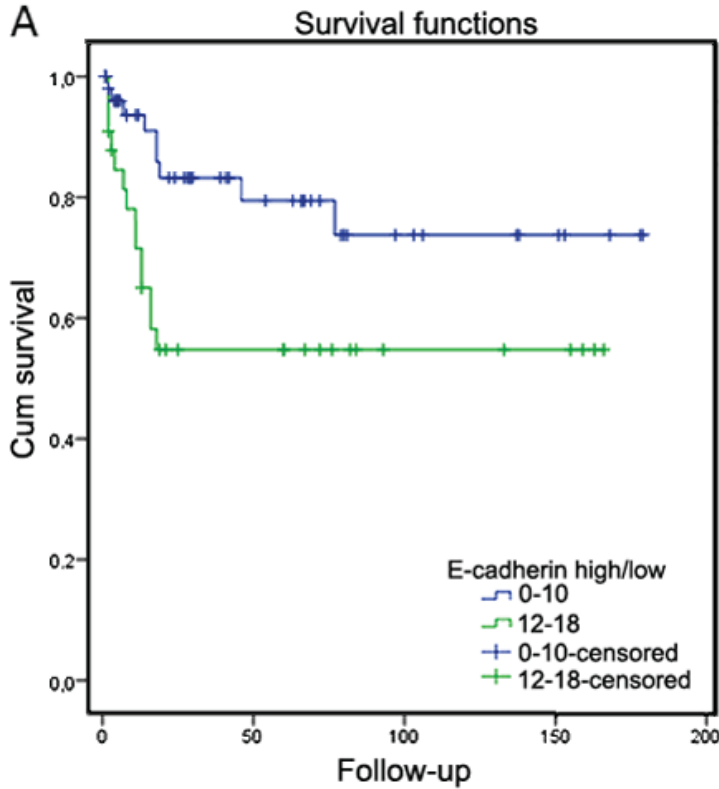

B

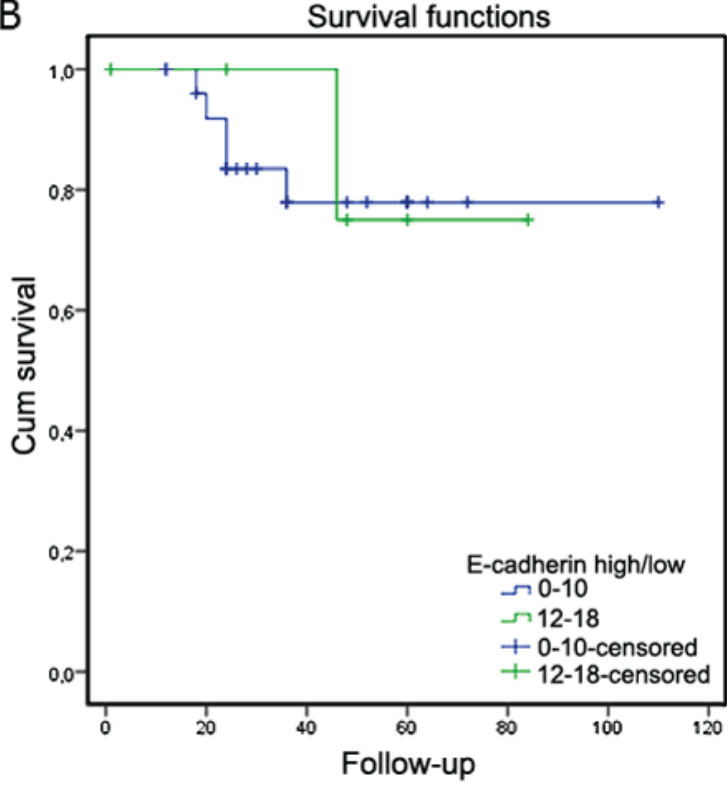

Figure 2. Kaplan-Meier curves for patients that had died of their disease, (A) Swedish (23 patients) and (B) Italian (6 patients), related to E-cadherin expression. Tumours were divided into low/medium (QS 0-10) and high (QS 12-18). Differences were investigated with Log Rank (Mantel-Cox) test showing significantly worse survival for Swedish patients with high E-cadherin tumours $(\mathrm{P}=0.016)$. No correlation was seen for Italian patients $(\mathrm{P}=0.842)$. 


\section{Acknowledgements}

Not applicable.

\section{Funding}

The present study was supported by grants from The Cancer Research Foundation in Northern Sweden, The Swedish Cancer Society (grant no. 1706 63), Västerbotten County Council, Umeå University (grant no. MEYS-NPSI-LO1413) and The Grant Agency of the Czech Republic (grant no. P206/12/G151).

\section{Availability of data and materials}

The datasets used during the present study are available from the corresponding author upon request.

\section{Authors' contributions}

NS, TW, PJC, LL, RoF, LC, LLM, LNS, ReF. GC, KD, KN designed the experiments, NS, TW, LB, LL, XG, PH, PJC, RoF, GT, FA, GC, KN performed data analysis. NS, TW, PJC, LB, LL, XG, PH, LC, LLM, RoF LNS, ReF, GT, GC, MS, GDO, FC, KD, GT, FA, KN interpreted the data, wrote and edited the manuscript. All authors read and approved the manuscript.

\section{Ethics approval and consent to participate}

The project was approved by the local Ethical Committee (dnr 01-057 and 03-201) and the use of surplus archived tissue after diagnosis was granted by the Ethical Committee, waiving the requirement for informed consent.

\section{Patient consent for publication}

Not applicable.

\section{Competing interests}

The authors declare that they have no competing interests.

\section{References}

1. Ng JH, Iyer NG, Tan MH and Edgren G: Changing epidemiology of oral squamous cell carcinoma of the tongue: A global study. Head Neck 39: 297-304, 2017.

2. Bello IO, Soini Y and Salo T: Prognostic evaluation of oral tongue cancer: Means, markers and perspectives (I). Oral Oncol 46 : 630-635, 2010

3. Bello IO, Soini Y and Salo T: Prognostic evaluation of oral tongue cancer: Means, markers and perspectives (II). Oral Oncol 46 636-643, 2010.

4. Scully C and Bedi R: Ethnicity and oral cancer. Lancet Oncol 1: $37-42,2000$

5. Wu H, Lotan R, Menter D, Lippman SM and Xu XC: Expression of E-cadherin is associated with squamous differentiation in squamous cell carcinomas. Anticancer Res 20: 1385-1390, 2000.

6. Foschini MP, Leonardi E, Eusebi LH, Farnedi A, Poli T, Tarsitano A, Cocchi R, Marchetti C, Gentile L, Sesenna E, et al Podoplanin and E-cadherin expression in preoperative incisional biopsies of oral squamous cell carcinoma is related to lymph node metastases. Int J Surg Pathol 21: 133-141, 2013.
7. Foschini MP, Cocchi R, Morandi L, Marucci G,Pennesi MG, Righi A, Tosi AL, de Biase D, Pession A and Montebugnoli L: E-cadherin loss and Delta Np73L expression in oral squamous cell carcinomas showing aggressive behavior. Head Neck 30: 1475-1482, 2008.

8. Bosch FX, Andl C, Abel U and Kartenbeck J: E-cadherin is a selective and strongly dominant prognostic factor in squamous cell carcinoma: A comparison of E-cadherin with desmosomal components. Int J Cancer 114: 779-790, 2005.

9. Zhang P, Cao HY, Bai LL, Li WN, Wang Y, Chen SY, Zhang L, Yang LH, Xu HT and Wang EH: The high expression of TC1 (C8orf4) was correlated with the expression of $\beta$-catenin and cyclin D1 and the progression of squamous cell carcinomas of the tongue. Tumour Biol 36: 7061-7067, 2015.

10. van der Velden LA, Schaafsma HE, Manni JJ, Ramaekers FC and Kuijpers W: Cytokeratin expression in normal and (pre)malignant head and neck epithelia: An overview. Head Neck 15: 133-146, 1993.

11. Park JM, Jung CK, Choi YJ, Lee KY, Kang JH, Kim MS and $\mathrm{Hu} \mathrm{HJ}$ : The use of an immunohistochemical diagnostic panel to determine the primary site of cervical lymph node metastases of occult squamous cell carcinoma. Hum Pathol 41: 431-437, 2010.

12. Becker MT, Shores CG, Yu KK and Yarbrough WG: Molecular assay to detect metastatic head and neck squamous cell carcinoma. Arch Otolaryngol Head Neck Surg 130: 21-27, 2004.

13. Ernst J, Ikenberg K, Apel B, Schumann DM, Huber G, Studer G, Rordorf T, Riesterer O, Rössle M, Korol D and Bredell MG: Expression of CK19 is an independent predictor of negative outcome for patients with squamous cell carcinoma of the tongue. Oncotarget 7: 76151-76158, 2016.

14. Sgaramella N, Coates PJ, Strindlund K, Loljung L, Colella G, Laurell G, Rossiello R, Muzio LL, Loizou C, Tartaro G, et al: Expression of p16 in squamous cell carcinoma of the mobile tongue is independent of HPV infection despite presence of the HPV-receptor syndecan-1. Br J Cancer 113: 321-326, 2015.

15. Sgaramella N, Lindell Jonsson E, Boldrup L, Califano L, Coates PJ, Tartaro G, Lo Muzio L, Fåhraeus R, Colella G, Dell'Aversana Orabona G, et al: High expression of podoplanin in squamous cell carcinoma of the tongue occurs predominantly in patients $\leq 40$ years but does not correlate with tumour spread. J Pathol Clin Res 2: 3-8, 2015.

16. Detre S, Saccani Jotti G and Dowsett M: A 'quickscore' method for immunohistochemical semiquantitation: Validation for oestrogen receptor in breast carcinomas. J Clin Pathol 48: 876-878, 1995.

17. Massano J, Regateiro FS, Januário G and Ferreira A: Oral squamous cell carcinoma: Review of prognostic and predictive factors. Oral Surg Oral Med Oral Pathol Oral Radiol Endod 102: 67-76, 2006.

18. Chang HW, Chow V, Lam KY, Wei WI and Yuen A: Loss of E-cadherin expression resulting from promoter hypermethylation in oral tongue carcinoma and its prognostic significance. Cancer 94: 386-392, 2002.

19. Strindlund K, Troiano G, Sgaramella N, Coates PJ, Gu X, Boldrup L, Califano L, Fahraeus R, Muzio LL, Ardito F et al: Patients with high c-MYC-expressing squamous cell carcinomas of the tongue show better survival than those with low- and medium-expressing tumours. J Oral Pathol Med 46: 967-971, 2017.

20. Greco A, de Virgilio A, Rizzo MI, Pandolfi F, Rosati D and de Vincentiis M: The prognostic role of E-cadherin and $\beta$-catenin overexpression in laryngeal squamous cell carcinoma. Laryngoscope 126: E148-E155, 2016.

21. Giraldi L, Panic N, Cadoni G, Boccia S and Leoncini E: Association between Mediterranean diet and head and neck cancer: Results of a large case-control study in Italy. Eur J Cancer Prev 26: 418-423, 2017.

22. Filomeno M, Bosetti C, Garavello W, Levi F, Galeone C, Negri E and La Vecchia C: The role of a Mediterranean diet on the risk of oral and pharyngeal cancer. Br J Cancer 111: 981-986, 2014.

23. Lee PN and Hamling J: Systematic review of the relation between smokeless tobacco and cancer in Europe and North America. BMC Med 7: 36, 2009.

24. Al-Hebshi NN, Alharbi FA, Mahri M and Chen T: Differences in the bacteriome of smokeless tobacco products with different oral carcinogenicity: Compositional and predicted functional analysis. Genes (Basel) 8: pii: E106, 2017.

25. Winn DM, Lee YC, Hashibe M and Boffetta P; INHANCE consortium: The INHANCE consortium: Toward a better understanding of the causes and mechanisms of head and neck cancer. Oral Dis 21: 685-693, 2015.

This work is licensed under a Creative Commons Attribution-NonCommercial-NoDerivatives 4.0 International (CC BY-NC-ND 4.0) License. 